\title{
Instituições e conflitos no campo dos museus de Santa Catarina $^{1}$
}

\author{
Institutions and conflicts in the field of the museums of Santa Catarina
}

\author{
Rafael Pereira Oliveira² \\ Rosimeri Carvalho da Silva ${ }^{3}$
}

\begin{abstract}
Resumo
Neste estudo, analisamos os principais atores sociais que influenciaram a configuração do campo organizacional dos museus de Santa Catarina, entre os anos de 1987 e 2006. Para a análise, adotamos a perspectiva institucional - que nos permitiu observar os distintos graus de estruturação do campo organizacional no período - e acrescentamos um olhar atento tanto às posições ocupadas pelos principais atores que nele operam quanto aos meios que os capacitam para a definição e realização de seus objetivos; ou seja, seus recursos de poder.

Os dados foram coletados por meio de entrevistas semi-estruturadas, da observação participante e de documentos. Os resultados permitiram destacar, entre todos os atores, as atuações do Estado e do Núcleo de Estudos Museológicos (NEMU) da Universidade Federal de Santa Catarina (UFSC) no campo. O Estado apareceu como importante ator por meio de três estruturas de dominação: a Fundação Catarinense de Cultura (FCC), a coalizão de funcionários da sua diretoria de patrimônio e o Instituto do Patrimônio Histórico e Artístico Nacional (Iphan). Durante o período analisado, constatamos um distanciamento do Estado em relação ao campo, num contraponto à presença do NEMU, o qual surgiu como a mais relevante estrutura de dominação do campo, responsável por importantes alterações na sua configuração.
\end{abstract}

Palavras-chave: politicas culturais; museus; teoria institucional; poder; estudos organizacionais.

\begin{abstract}
The aim of this paper is to analyze the main social actors that had influenced the configuration of the organizational field of the museums of Santa Catarina between 1987 and 2006. For the analysis, we use the institutional perspective - which allowed us to observe the distinct degrees of structuration of the organizational field in the period; and we add a careful look to the positions occupied by the main actors who operate in it and the power resources they possess. Data were collected using half-structuralized interviews, participant observation and documents. The results allowed highlighting, among all actors, the performances of the State and the Center for Museums Studies of Federal University of Santa Catarina (UFSC) in the field. The State appeared as an important actor through three structures of domination: Santa Catarina Culture Foundation (FCC), the coalition of employees of its patrimonial direction and the Institute of National Artistic Heritage (Iphan). We conclude that the State distanced itself from the field during the analyzed period, contrasting to the presence of the Nemu, which appeared as the most excellent structure of domination of the field and responsible for important alterations in its configuration.
\end{abstract}

Key words: cultural policies; museums; institutional theory; power; organizational studies.

\footnotetext{
${ }^{1}$ Os autores agradecem ao revisor da revista, que contribuiu substancialmente com o formato final deste artigo.

${ }^{2}$ Servidor público federal atuando na Coordenação Geral de Direito Autoral da Secretaria de Políticas Culturais do Ministério da Cultura do Brasil. Mestre em Administração pela Universidade Federal de Santa Catarina. Endereço: Ministério da Cultura, Coordenação-Geral de Direito Autoral. Esplanada dos Ministérios BI. "B" - 20. andar - Brasília, DF - Brasil - CEP: 70068-900. E-mail: rafaeloliveira.cultura@gmail.com

${ }^{3}$ doutora em Administração pela École de Hautes Études Commerciales - HEC - França. Professora adjunta do Departamento de Ciências da Administração e do Mestrado em Administração da Universidade Federal de Santa Catarina. Endereço: CSE-CAD - Campus Trindade - Florianópolis - Santa Catarina - Brasil - CEP: 88040900 - E-mail: rosimeri@cse.ufsc.br

Artigo submetido em março 2008 e aceito em junho 2008
} 


\section{Introdução}

A percepção de que as instituições são fundamentais para a análise social tem obtido crescente importância nas ciências sociais desde a segunda metade do século XX. Um enfoque teórico em especial, o novo institucionalismo sociológico, tem sido bastante utilizado na análise de contextos sociais, principalmente, nos estudos organizacionais. Nesse enfoque, instituições são estruturas sociais duradouras - compostas de elementos simbólicos, de atividades sociais e de recursos materiais - que atingiram um alto grau de estabilidade. São transmitidas por gerações e têm como importante característica a resistência a mudanças (SCOTT, 2001). Assim, limitam a ação humana e conformam os atores e seus interesses, "estabelecendo os meios apropriados e definindo os resultados desejados" (DIMAGGIO; POWELL, 1999, p.68).

Embora considerando que a criação dessas regras e rotinas, mesmo que para trazer ordem e minimizar incertezas, seja fruto de "conflitos, contradições e ambigüidades" (DIMAGGIO; POWELL, 1999, p.68), os institucionalistas pouco consideram os aspectos relacionados a poder e conflito em seus indicadores de análise, limitando o olhar sobre a capacidade dos atores interferirem nas instituições e conseqüentemente produzirem mudanças no contexto institucional. A adoção de outras perspectivas teóricas tem sido experimentada por pesquisadores, na tentativa de complementar a análise das organizações, visto que a teoria institucional ainda se apresenta como um importante arcabouço teórico para estudá-las, especialmente, no nível do campo.

No estudo que apresentamos neste artigo utilizamos a perspectiva institucional para analisar a influência das políticas culturais na configuração do campo catarinense dos museus, de 1987 a 2006, com o objetivo de verificar a influência, nesse campo organizacional, das políticas culturais praticadas pelos governos que se sucederam no estado de Santa Catarina. Para a análise, adotamos a perspectiva institucional, que nos permitiu observar os distintos graus de estruturação do campo organizacional no período. Concordando com os diversos críticos desta teoria acerca da importância da categoria poder, acrescentamos um olhar atento, tanto às posições ocupadas pelos principais atores que nele operam, quanto aos meios que os capacitam para a definição e realização de seus objetivos; ou seja, para aquilo que Korpi (1985) chama de recursos de poder.

Os resultados apontaram para um campo que se estruturou no período, apresentando alterações significativas na sua configuração. Mas além disso, a perspectiva adotada permitiu, por meio do indicador "estruturas de dominação", de Scott (1994), identificar os atores que armazenaram mais recursos de poder e, analisando-se os tipos de recursos, também possibilitou perceber de que forma eles influenciaram o campo.

Neste artigo, analisamos os principais atores-sociais que influenciaram a configuração do campo organizacional dos museus de Santa Catarina, entre os anos de 1987 e 2006, tomando como base a pesquisa citada anteriormente. De abordagem predominantemente qualitativa, a pesquisa teve os dados secundários extraídos de documentos diversos dos arquivos da Fundação Catarinense de Cultura - como memorandos, comunicações internas, projetos e relatórios relevantes ao estudo -, além dos programas de campanha e relatórios de gestão dos governos estaduais e do Cadastro Nacional de Museus do Iphan.

Os dados primários foram coletados por meio de 19 entrevistas semi-estruturadas, com participantes da gestão pública estadual e integrantes de organizações museológicas. Os sujeitos da pesquisa foram selecionados por julgamento, identificados entre pessoas que integraram órgãos culturais públicos ou organizações museológicas, no período definido, escolhidos pela capacidade de trazerem informações relevantes ou por ocuparem posições estratégicas no campo. Além dessas entrevistas, foi realizada uma conversa com um grupo de 10 profissionais de museus que participavam do XXVIII Encontro do Núcleo de Estudos Museológicos, na qual colocamos em discussão a análise que realizamos sobre a configuração do campo, a influência dos atores e das políticas culturais. De maneira geral não houve discordâncias quanto a análise que apresentamos, mas algumas complementações.

É importante ressaltar que o envolvimento de um dos pesquisadores com o campo da cultura do Estado de Santa Catarina teve caráter central na coleta dos dados, possibilitando uma observação participante qualificada em diversos eventos envolvendo atores e fatos importantes do campo. Vale citar, entre outros, a participação em reuniões de formatação do Sistema Estadual de Museus e em palestras e encontros relativos à museologia. 
Durante todos estes momentos o pesquisador teve a oportunidade de realizar entrevistas informais (conversas do cotidiano) com o intuito de identificar as percepções, valores, relacionamentos e comportamento dos atores perante o campo (VIEIRA; PEREIRA, 2005).

\section{Museu como instituição}

A decisão por escolher o campo dos museus como universo desta pesquisa se deu pela sua importância no campo da cultura catarinense, particularmente, pela sua capilaridade ${ }^{1}$ e pela característica de seus acervos, que por serem majoritariamente históricos, reforçam e ressignificam as identidades locais. Além disso, museu é habitualmente definido como instituição, justificando assim a adoção da perspectiva institucional de análise.

O termo instituição tanto pode ser usado para definir uma organização considerada importante ou relevante, quanto para conceituar um procedimento organizado e estabelecido, que se apresenta na forma de regras que compõem a sociedade e são reproduzidas rotineiramente (JEPPERSON, 1999). O museu se enquadra em ambas definições: Como organização, pode se configurar tanto como espaço responsável pela guarda e disseminação da cultura material e imaterial das sociedades, quanto como centro de inovações culturais e tecnológicas. Como procedimento, o museu pode ser definido como meio pelo qual os indivíduos dão significado à sua história, às suas relações, àquilo que são. Quando isso ocorre, temos a institucionalização, o que Jepperson (1999) chama de naturalização de processos de reprodução que antes ocorriam pela ação.

Como organizações, os museus operam por meio de trocas simbólicas e materiais com o ambiente no qual estão inseridos. A percepção da existência desses dois ambientes é uma das contribuições da teoria institucional e possibilita enxergar a sobrevivência das organizações como resultado da busca por atingir a eficiência no ambiente técnico e a legitimidade, no institucional (DIMAGGIO; POWELL, 2005).

O conceito de ambiente, ampliado pela perspectiva institucional, é fundamental para se compreender os processos que ocorrem no campo dos museus. Em função da natureza de suas atividades e de seus objetivos sociais, eles são organizações que "operam em um ambiente altamente institucionalizado, sofrendo pressões tanto de setores organizados da sociedade como de órgãos governamentais, que geralmente as controlam" (GOULART; MENEZES; GONÇALVES, 2003, p.133). Esses ambientes institucionalmente complexos se caracterizam "pela elaboração de regras e exigências às quais as organizações devem se ajustar, se desejam receber apoio e legitimidade" (SCOTT; MEYER, 1999, p.170).

Meyer e Rowan (1999) afirmam que certas atividades possuem um significado ritual que se sobrepõe a sua eficiente atuação e que a conformidade com as regras institucionais, freqüentemente, entra em conflito com os critérios de eficiência. É isso que garante, segundo os autores, que uma universidade mantenha determinados cursos, independente da demanda. A mesma lógica pode ser usada com relação aos museus e suas políticas de conservação e restauração, por exemplo. Uma vez que os museus não operam pela lógica da eficiência - ou seja, não estão direcionados para a troca de bens e serviços em um mercado, mas carregam e representam conjuntos de valores e crenças -, sua sobrevivência passa, essencialmente, pela sua legitimação no ambiente, pela sua conformação às normas socialmente aceitas. No entanto, para se compreender os processos de institucionalização dos formatos organizacionais é necessário trabalhar além do nível das organizações, buscando uma compreensão da construção histórica do contexto organizacional, ou seja, do campo (VIEIRA; CARVALHO, 2006).

Os museus formam um campo próprio, denominado "museal", onde valores, critérios, práticas e discursos específicos são reconhecidos (SANTOS, 2004). A dinâmica que ocorre entre as diversas organizações que operam num mesmo espaço pode ser compreendida por meio da noção de "campo organizacional", elaborada por DiMaggio e Powell (1999) e elemento central da teoria institucional. Esse conceito identifica uma rede formada por várias organizações que mantêm relações mútuas de dependência, que compartilham o mesmo sistema de valores e que estão sujeitas ao mesmo sistema regulatório (VIEIRA; CARVALHO; SILVA, 2007).

O conceito de campo está associado à idéia de que "organizações sobrevivem ao darem atenção às ligações diretas e indiretas, objetivas e subjetivas, com atores que nem sempre controlam recursos materiais de interesse 
direto de uma organização" (CARVALHO; VIEIRA, 2003). Assim, o campo museal inclui não somente os museus, mas outros atores que de alguma forma mantêm relações com eles, ainda que indiretas. Dessa forma, um passo importante para a delimitação de um campo organizacional é a identificação dos atores que o constituem: as organizações governamentais, as associações profissionais, as universidades e os órgãos financiadores, entre outros.

A análise do campo e do processo de institucionalização implica a identificação das relações entre esses atores e dos valores compartilhados, dado que o processo pode se apresentar em diferentes etapas, desde um campo em pré-formação - no qual as organizações apresentam poucas relações e atuam de maneira isolada e independente - até um campo institucionalizado, caracterizado por um elevado número de relações entre as organizações e valores fortemente compartilhados. Etapas intermediárias apresentam, num estágio no qual o campo começa a se formar, o aparecimento de relações entre as organizações e um processo de concentração do campo. Em um terceiro estágio, aparece um número maior de relações entre as organizações e o surgimento de valores convergentes (VIEIRA; CARVALHO, 2006).

Nesta pesquisa, o grau em que o campo se encontra institucionalizado (ou seja, o seu grau de estruturação) foi observado por meio de cinco indicadores, baseados em DiMaggio e Powell (2005) e Scott (1994):

- interação - grau de interação entre as organizações no campo. Troca de informações, relações de dependência e de cooperação e existência de redes;

- dominação - formação e atuação de estruturas de dominação ou de padrões de coalizão. Quantidade de organizações do campo que são referência de modelos de gestão e de procedimentos para as outras;

- informação - incremento da carga de informação com a qual as organizações do campo devem operar;

- comunalidade - grau de percepção, entre as organizações do campo, de que fazem parte de um empreendimento comum e;

- profissionalização - grau de capacitação dos profissionais que atuam nas organizações do campo.

\section{Museu e campo museal como arenas}

Além de configurar-se como espaço e meio de institucionalização de valores, regras e mitos, o museu é também uma arena onde se confrontam diferentes interesses. É um campo de tensão e de contradição que se configura na relação entre o que deve ser preservado e o que deve ser esquecido, entre o diferente e o igual, entre o ontem e o amanhã, entre o poder a resistência. Trata-se de um lugar de produção simbólica e de transformação dos sentidos, de uma "ponte entre tempos, espaços, indivíduos, grupos sociais e culturas diferentes" (CHAGAS, 2005, p.24).

Os conflitos, resultados de interesses divergentes, podem ser resolvidos ou perpetuados por meio de vários tipos de jogos de poder (MORGAN, 1996). Crozier (1983, p.18) afirma que "não há sociedade possível sem poder", levando-se em conta que "nenhuma relação concreta entre indivíduos ou grupos humanos poderá jamais ser despojada de sua dimensão de poder".

Esses conflitos também estão presentes no processo de estruturação de um campo organizacional, visto que "os esquemas de significados, os cenários e os símbolos nascem não somente de processos de interpretação, mas também de processos de conflito" (HALL; TAYLOR, 2003, p.218), o que torna a consideração do elemento "poder" essencial à compreensão desses processos. Para Ranson, Hinnings e Greenwood (1980), estruturar é privilégio de alguns atores organizacionais, porquanto a disposição de determinados grupos e indivíduos dentro de uma estrutura representa uma grande força capaz de impactá-la.

Uma vez que a configuração de um campo é resultado da disputa entre os principais atores sociais para fazerem prevalecer seus valores, e com isso realizarem seus objetivos, essa configuração sofre mudanças, à medida que ocorre alguma alteração na posição relativa dos atores, como afirmam Machado-da-Silva et al (2003, p.180). Para esses autores, os "conflitos de interesses entre grupos sociais" e as "transformações estruturais nas 
relações de poder entre entidades sociais" estão entre as origens e possibilidades da incorporação de novos valores e práticas culturais no ambiente institucional. O mesmo vale para a consideração de DiMaggio (1988 apud SCOTT, 2001, p.,72) sobre o surgimento de novas instituições, que "nascem quando atores organizados com recursos suficientes [...] vêem nisso uma oportunidade para realizar seus interesses". Fica clara, então, a importância que tem o poder na configuração de um campo.

Apesar de muitos estudos da perspectiva institucional não considerarem esse aspecto, pareceu-nos essencial o esforço de incluir a percepção do poder dos atores na análise do campo museal. Nesse sentido, para a análise das configurações do campo organizacional deste estudo, demos ênfase às organizações de referência, por meio do indicador dominação, considerando que os atores ocupam posições em função de recursos que os capacitem de alguma forma a isso.

Philips, Lawrence e Hardy (2000 apud VIEIRA; CARVALHO; SILVA, 2007) já haviam ressaltado que a mudança efetiva em um campo organizacional é contingente das relações de poder do próprio campo. Além disso, segundo os autores, "para que um processo de colaboração produza mudanças no campo, é necessário que seus participantes possuam os recursos de poder necessários" (VIEIRA; CARVALHO; SILVA, 2007, p.7). A análise dos recursos de poder com que contam os atores parece então apropriada.

Para Faria (2004), poder é a capacidade que tem um indivíduo ou grupo de definir e realizar seus interesses. Recursos de poder podem, então, ser definidos como atributos (capacidades ou meios) de atores (indivíduos ou coletividades) que os capacitam para a definição e realização de seus objetivos nas relações com outros atores em um campo (KORPI, 1985).

Neste estudo, entendemos recursos de poder como os "recursos buscados pelos atores, visando a melhores resultados e ao domínio sobre outros atores". São esses recursos que determinam o poder de negociação de cada ator no campo, os quais podem buscar seu controle de forma direta, "pela interação com outros atores (negociação) ou por ajudas públicas estatais e não-estatais” (PAULILLO, 2001, p.257).

$\mathrm{Na}$ literatura de maior divulgação na área de administração, os recursos de poder são também chamados de fontes, e dão a quem os possui "uma variedade de meios para ampliar os seus interesses, resolvendo ou perpetuando os conflitos [...]" (MORGAN, 1996, p.164). Esses recursos (ou fontes) de poder podem ser de ordem associativa, simbólico-cultural, financeira, organizacional, política ou tecnológica, ou, ainda, serem recursos ligados à autoridade ou ao conhecimento especializado (MORGAN, 1996; PAULILLO, 2001).

A seguir, a partir das perspectivas apresentadas, analisamos as principais características do campo dos museus de Santa Catarina e os atores que, entre os anos de 1987 e 2006, influenciaram as configurações do campo. Ressaltamos que a configuração do campo foi compreendida através do seu grau de estruturação, da posição ocupada pelos principais atores que nele operam e seus recursos de poder.

\section{0 campo museal de Santa Catarina (1987-2006)}

Antes de entrarmos no período em questão, vale compreender alguns aspectos da formação do campo museal catarinense, que em 1974 contava com 33 museus $^{2}$. Foi entre os anos 1980 e $2000^{3}$ que mais de $70 \%$ das instituições museais catarinenses surgiram, chegando no final de 2006 ao total de 181 (IPHAN, 2006). Alguns fatores podem ter sido responsáveis pela multiplicação do número de museus nesse período, como o desenvolvimento descentralizado, o fortalecimento dos municípios e as práticas políticas que incentivaram a preservação do patrimônio.

Em diversas regiões do mundo houve um aumento no número de museus a partir de 1980, fruto tanto de um processo de "comercialização das narrativas e dos elementos simbólicos preservados pelos museus", quanto de um "movimento que tornou mais diversificado o processo de preservação do passado" (SANTOS, 2004, p.59). Em Santa Catarina, essas explicações assumem contornos mais específicos. A mistura étnica presente na composição do estado lhe confere o caráter de "um estado composto de fragmentos de diversas nações" (OLIVEN, 1992). Desde os anos 1970, foi sendo construído um projeto de política cultural apoiado na 
aceitação controlada das diferenças, na construção de uma identidade catarinense composta de um mosaico de culturas, que garantia a unidade necessária para a integração política, econômica e cultural, ao mesmo tempo em que se tornava uma valiosa fonte de exploração turística (SAYÃO, 2004).

Esse projeto, caracterizado pelo reforço às tradições advindas das rotas migratórias, gerou, a partir da década de 1980, um processo de hipervalorização das diversas culturas (em especial da germânica, da italiana e da lusoaçoriana), por meio do incremento do intercâmbio com os países de origem dos imigrantes e da criação de "festas típicas". Esse fenômeno, associado ao processo de urbanização e ao fortalecimento dos municípios, pode ter sido responsável pelo surgimento de tantos museus históricos de pequeno porte ligados às estruturas públicas municipais a partir dos anos 1980, que caracteriza o início da estruturação desse campo organizacional.

No entanto, a distribuição econômica e cultural de Santa Catarina, fruto de peculiaridades étnicas e geográficas, produziu campos regionais com características, valores e lógicas muito distintas. A estruturação do campo dos museus catarinense se caracterizou por essa regionalização. Em todas as regiões, organizações passaram a se destacar por sua atuação nuclear, ou seja, por serem referência para outros museus geograficamente próximos, configurando campos que em alguns momentos foram bastante independentes, com pouca interação com outras regiões, mas que em outros momentos foram mais interconectados.

Os 181 museus existentes em Santa Catarina estão distribuídos por 89 municípios, representando (30,38\%) da totalidade de cidades do estado. A média nacional é de $11,67 \%$, e apenas seis estados possuem museus distribuídos entre 20 a 30\% de seus municípios. Além disso, Santa Catarina é o estado que possui a menor concentração de museus em sua capital, com apenas 23 museus em Florianópolis, o que equivale a 12,71\% do total do estado.

Do campo museal fazem parte, além dos museus, outros atores sociais que em determinado momento mantêm uma relação de dependência mútua, compartilham o mesmo sistema de valores e estão sujeitos aos mesmos processos regulatórios (SCOTT, 1994), estando aptos a interferir na sua institucionalização. Entre eles, aqueles que intermediam a comunicação entre o artista e demais atores do campo (financiadores, Estado e organizações culturais, entre outros), além de organizarem os recursos necessários para a concepção do projeto cultural. São conhecidos como produtores ou agentes culturais.

No campo analisado, durante o período em questão, a presença mais efetiva desses atores surge somente a partir de meados dos anos 1990, quando a crise financeira, exacerbada pela orientação neoliberal de recuo do Estado das responsabilidades sociais, levou a uma diminuição dos recursos financeiros destinados à manutenção dos acervos e da estrutura dos museus. Isso, aliado à política de incentivos fiscais instalada no país, levou os museus a adotarem técnicas de marketing para ampliar a captação de recursos junto às empresas privadas e criou um ambiente favorável ao surgimento desses profissionais.

No entanto, constatamos que a atuação desses agentes no campo catarinense começa a ter alguma relevância no início dos anos 2000, embora uma significativa interferência sua na estruturação desse campo ainda esteja por vir. O mesmo processo de inserção no campo ocorre com as organizações empresariais que financiam projetos culturais por meio do patrocínio integrado às suas estratégias de comunicação.

Em virtude do acervo predominantemente histórico, o campo museal catarinense ainda se apresenta fortemente ligado aos investimentos públicos ou público-privados (referimo-nos aos editais privados com recursos de incentivos fiscais ou realizados por organizações sem fins econômicos). A partir de 1996, alguns dos principais museus catarinenses passaram a contar com recursos privados da Fundação Vitae, uma associação que destinou recursos de fontes internacionais a projetos de educação, cultura e promoção cultural no Brasil. Essa organização internacional financiou projetos museológicos em todo o país, de 1986 a 2006. No entanto, em Santa Catarina, em nove anos foram 11 prêmios que contemplaram seis instituições. A constatação de que foram poucos os museus que conquistaram o apoio desse que foi um dos mais importantes financiadores privados do país mostra a fragilidade das organizações do campo. Observamos que essa premiação ampliou a legitimidade de poucos museus no campo, contribuindo para a manutenção de suas posições de destaque. 
A partir de 2003, tivemos a entrada no campo, como financiadores, de empresas públicas como Petrobrás, Caixa Econômica Federal e BNDES, que passaram a lançar editais de apoio aos museus, em consonância com as políticas do Ministério da Cultura (MinC). Essa modalidade de financiamento, junto com outras seleções públicas realizadas pelo MinC, compõe uma nova e ampliada fonte de recursos para os museus, influenciando a configuração do campo, na medida em que pressionam a estruturação das organizações e demandam a presença de profissionais mais capacitados.

Também fazem parte do campo, instituições de ensino que estejam desenvolvendo projetos que envolvam áreas afins, além das associações de profissionais e de outras entidades organizadas vinculadas ao setor museológico. Segundo DiMaggio (1999, p.333), "a teoria institucional presta especial atenção a organizações como as agências do governo e as associações de profissões", que não se encontram diretamente vinculadas à atividade fim do campo, mas participam dele, influenciando ou limitando as organizações que nele produzem bens ou serviços.

Além da presença da Universidade Federal de Santa Catarina (UFSC) no campo, por meio do Núcleo de Estudos Museológicos (NEMU), entidade que receberá um destaque mais adiante neste artigo, outras instituições de ensino superior exerceram influência no campo. Foi o caso da Universidade Comunitária Regional de Chapecó (UnoChapecó), por meio do Centro de Estudos da Memória do Oeste Catarinense (CEOM).

O CEOM surgiu em 1986 como um programa de extensão, impulsionado por uma parceria com a Fundação Catarinense de Cultura (FCC), a qual objetivava fazer daquela instituição um pólo disseminador das ações do governo no Oeste catarinense. Até hoje atua como importante agência naquela região, estabelecendo a comunicação entre as instituições ligadas à memória dos municípios da região e provendo-as com capacitação e apoio técnico. O Oeste catarinense é a região mais distante da capital, respondendo pela maior quantidade de museus no estado, os quais são de pequeno porte e predominantemente ligados às estruturas municipais. Esta distância da capital pode ter contribuído para que estruturas de dominação e organizações de referência próprias deste espaço tenham surgido.

O padrão de dominação que se estabelece nessa região é caracterizado por uma coalizão de pequenas organizações em torno de uma estrutura maior (no caso o CEOM), podendo ser entendido a partir da instabilidade do ambiente e também pela regionalização característica de Santa Catarina. DiMaggio e Powel (1999) afirmam que quanto mais instáveis forem os ambientes, mais as organizações dominantes assumem papel na definição das regras do jogo, que são amplamente aceitas pelos outros atores, mediante estratégias de controle.

Entre os recursos de poder que habilitaram o CEOM a tornar-se uma organização dominante, estão seu corpo técnico especializado, a legitimação que o Estado lhe concedeu e a compreensão da lógica cultural da região. Dessa forma, tem conseguido desenvolver um trabalho que lhe permite atuar onde o Estado não consegue chegar, pois conhece mais de perto as necessidades e demandas da região, além de dominar a lógicas dos pequenos municípios. Com isso, consegue interferir na realidade das instituições (predominantemente ligadas às estruturas públicas municipais) com maior eficácia, interferindo em práticas já institucionalizadas e, por isso, de difícil mudança.

A partir do final dos anos 1990, quando em todo o país as instituições privadas começaram a atuar de forma mais efetiva na educação, organizações de ensino superior fortaleceram-se por todo o estado de Santa Catarina, tornando-se importantes na estruturação regional do campo, por meio do desenvolvimento de projetos de pesquisa e extensão ou administrando unidades museais.

Em 2004, a Universidade Barriga Verde - instituição privada de ensino superior sediada em Orleans, no sul do estado, e que mantém o Museu ao Ar Livre - implantou o terceiro curso de museologia do país. Desde 1984, existe uma lei federal (n⿳⺈ 7.287/84) que exige a presença de museólogos (vindos de cursos de graduação, de mestrado ou de doutorado) nos museus. Parece que a adoção dessa norma no campo fez com que a instituição decidisse produzir uma capacitação específica, criando o Curso de Bacharelado em Museologia, com habilitação para museus de história. O curso, que formou a primeira turma no final de 2007, tem 
gradativamente melhorado sua posição no campo, assumindo um importante papel na formação e no intercâmbio de profissionais. Uma vez que há somente dois profissionais registrados atuando em Santa Catarina, podemos supor que a entrada de novos profissionais impactará a configuração do campo, dada a importância atribuída por Meyer e Rowan às profissões.

Para DiMaggio e Powell (2005, p.80) as associações e as redes de profissionais são os meios pelos quais "novos modelos são rapidamente difundidos". As universidades, as associações profissionais e os cursos de treinamento são importantes veículos de transmissão de práticas e normas sobre comportamento organizacional e profissional.

Entre 1994 e 1998, a 11를 Superintendência Regional do Iphan em Santa Catarina promoveu uma série de oficinas de conservação e restauro pelo estado, que resultaram em um aumento no volume de informações em circulação e também contribuíram com a formação de profissionais das áreas de conservação e restauração de acervos. Essa categoria de profissionais já vinha se estruturando no estado desde 1987, quando foi criada a Associação Catarinense de Conservadores e Restauradores de Bens Culturais (ACCR), primeira associação do gênero na região Sul. Nesse sentido, acreditamos que a capacitação desses profissionais, aliada à organização já existente, pode ter contribuído bastante para a institucionalização de novas normas e práticas no campo.

Ainda a respeito da capacitação e da rede de profissionais, destacamos o curso de especialização latu sensu em Museologia da Universidade do Estado de Santa Catarina (Udesc), realizado entre 1999 e 2000. O curso formou 24 especialistas, institucionalizou procedimentos e legitimou pessoas que já atuavam na área. Além de contribuir para a profissionalização do campo, gerou laços de amizade entre os estudantes que se mantiveram por meio de trocas de experiências entre as organizações nas quais passaram a atuar.

DiMaggio e Powell (1999) destacam a importância das organizações dominantes no campo, ou seja, aquelas que são referência ou modelo para as outras, por estarem legitimadas ou deterem fontes de recursos importantes. Esse é o caso do Centro de Estudos da Memória do Oeste Catarinense (CEOM), já analisado, assim como de outra importante estrutura de dominação do campo: o Núcleo de Estudos Museológicos da Universidade Federal de Santa Catarina (NEMU/ UFSC).

O NEMU foi criado em 1997 e nasceu da junção de interesses de pessoas ligadas a duas importantes organizações da área do patrimônio que atuavam no campo: a gerente de museus da Fundação Catarinense de Cultura (FCC) e o diretor do Museu Universitário da UFSC. Essas pessoas reuniam os recursos de poder necessários para a criação dessa que consideramos a mais importante estrutura de dominação do campo.

De posse do recurso organizacional que lhes legitimavam no campo, associado ao recurso político e ao conhecimento especializado, essas pessoas empreenderam ações que se caracterizaram mais por iniciativas individuais do que por políticas institucionais. Trata-se de profissionais com grande inserção no campo, que há anos eram demandados a dar orientações a museus de todo o estado. No entanto, esse atendimento carecia de respaldo e estrutura institucional, resultando em ações isoladas e descontinuadas.

Na Fundação Catarinense de Cultura, a gerente de museus trabalhava com uma estrutura mínima e contra uma política de patrimônio que privilegiava os tombamentos, como veremos mais adiante nesta análise. Na UFSC, além de uma política institucional, o carisma e a competência técnica do diretor do Museu Universitário, um dos primeiros museólogos em Santa Catarina, tornaram-no uma referência para os pequenos museus espalhados pelo estado.

Paralelamente, o Iphan/SC vinha realizando a série de oficinas já relatada, o que estimulou o debate e a formação de uma comissão com o intuito de pensar uma rede de integração dos museus catarinenses. Os trabalhos dessa comissão, com o respaldo da gerente de museus da FCC e do diretor do Museu Universitário, resultaram na definição do formato do NEMU, como núcleo gerador de encontros periódicos e descentralizados.

A continuidade dos trabalhos do núcleo por 10 anos pode ser creditada à estratégia de formalização da estrutura na UFSC, a instituição menos "contaminada" pela instabilidade político-eleitoreira relacionada com as trocas 
de governo no estado. Se por um lado, a presença de representantes do Iphan e da FCC na implantação do núcleo foi fundamental para sua legitimação, por outro, a saída dessas pessoas de suas instituições contribuiu para que o NEMU fosse se institucionalizando como uma ação exclusiva da UFSC e assumisse o vácuo deixado pelo Estado na área.

A partir de 1997, com o início das atividades do NEMU, há um aumento gradual na troca de experiências e informações entre instituições museais de todo o estado, gerando alteração significativa no grau de interação entre os atores-sociais no campo. As ações do NEMU estão focadas na capacitação dos trabalhadores de museus, por meio de encontros regionais (em média, três por ano) que envolvem conferências, comunicações e oficinas. O evento, itinerante, ocorre até hoje, em parceria com alguma instituição em cada região; ora uma prefeitura, ora uma instituição de ensino superior. Como muitos participantes acompanham diversas edições do evento, os encontros ultrapassam em abrangência a região onde são realizados, produzindo com isso uma interação no campo diferente do padrão que vinha ocorrendo até então, que era mais restrito aos museus da mesma região.

Diversos depoimentos reforçam que a atuação do NEMU contribuiu para o aumento do grau de interação entre as organizações num nível diferente do que vinha ocorrendo até então (de caráter mais regionalizado), pois possibilitou uma troca de informações entre profissionais de diversas regiões, construindo relações de cooperação entre as organizações e aumentando a sensação de comunalidade no campo.

Muitos profissionais adquiriram todo o seu conhecimento formal na área por meio das oficinas do NEMU, e com a constância das oficinas passaram a atuar de forma mais efetiva nas suas instituições, diminuindo sua suscetibilidade para ser objeto de descarte ligado aos interesses políticos. Uma vez que a natureza da maioria dos museus catarinenses é pública, os cargos dessas instituições estão subordinados a interesses políticos, havendo grande rotatividade, vinculada à alternância no poder municipal ou estadual. A realidade aponta para uma grande parcela de museus que são ocupados por administradores e funcionários desqualificados, muitas vezes, escolhidos não pela capacidade técnica, mas por relações sociais, afinidades políticas, pouca qualificação para outra atividade ou mesmo como forma de castigo.

A existência de muitos museus de pequeno porte ligados às prefeituras reforça a existência de práticas de punição, como forma de pressão política, ou mesmo como premiação concedida a pessoas que ajudaram em período de campanha política. Entrevistados relataram que muitos funcionários são enviados para os museus por serem desafetos dos prefeitos. Por vezes, trata-se de funcionários da prefeitura que fazem oposição a atual administração e que, então, são castigados com a incumbência de cuidarem de museus, "aquela casinha esquecida, com um monte de coisas abandonadas, cheia de poeira e paranhos".

Depoimentos afirmam que uma parte significativa da demanda por informações técnicas e cursos de capacitação, na década de 1990, vinha de pessoas que se viam "com essa panela de pressão na mão", tendo que lidar com uma realidade que desconheciam. Diante disso, percebemos que o NEMU, por meio da qualificação técnica, contribuiu fortemente para a legitimação das pessoas que trabalham nos museus, diminuindo a rotatividade de profissionais nessas instituições, além de ter aumentado o grau de percepção, entre as organizações, de que fazem parte de um empreendimento comum. Dessa forma, minimizou um dos principais problemas dos museus catarinenses - ainda mais grave do que a falta de recursos financeiros -, a profissionalização, visto que a pouca qualificação inviabiliza o acesso às fontes de financiamento existentes, que cada vez mais requerem projetos bem formulados e exeqüíveis.

Outro ator que exerce forte influência no processo de institucionalização é o Estado. Sua capacidade de coagir legitimamente faz dele um ator distinto, que exerce autoridade legal sobre outras organizações, operando basicamente via processo normativo (SCOTT, 2001). DiMaggio e Powell (1999) consideram que, junto com as categorias profissionais, o Estado está entre os principais atores institucionais, destacando-se como um dos grandes racionalizadores da segunda metade do século XX.

Como "ator coletivo", o Estado pode exercer uma série de ações, como outorgar alvarás especiais, alocar recursos-chave, impor taxas e exercer o controle regulatório. Como "estrutura institucional", cabe ao Estado prover diferentes arenas nas quais os conflitos entre as organizações ou sistemas de organizações podem ser 
julgados. Ele tem papel determinante nas condições da propriedade e do controle dos meios de produção (SCOTT, 2001).

As organizações tendem a conformar-se às regras do Estado (DIMAGGIO; POWELL, 2005), que é responsável pelo planejamento, implementação e avaliação das políticas culturais. No caso do campo objeto deste estudo, o Estado é também o principal gestor das organizações museais, que em função de seus objetivos sociais e culturais estão predominantemente atreladas a investimentos públicos. A maioria dos museus brasileiros (mais de 80\%, segundo o Cadastro Nacional de Museus do Iphan) são instituições públicas. Em Santa Catarina, ${ }^{4} 70 \%$ dos museus são estaduais ou municipais.

Carvalho, Pacheco e Guimarães (2004), que analisaram a importância do Estado no campo da cultura a partir de diversas investigações, ${ }^{5}$ concluíram que, apesar deste vir atuando no sentido de incentivar a auto-sustentação das organizações culturais e estar afastando-se de funções que historicamente eram suas, ainda se mantém como um ator determinante na configuração e estruturação do campo das organizações culturais. Em nossa pesquisa, que dividiu a análise da atuação do poder público estadual no campo em cinco momentos, considerando os períodos governamentais como referência, ficou evidente a sua importância, como resumimos a seguir.

\section{0 papel do poder público estadual no campo dos museus catarinenses}

No primeiro momento (de 1987 a 1990), verificamos uma melhoria na estrutura organizacional do Estado para atender ao campo, impulsionada pelo contexto nacional. Em 1985 é criado o Ministério da Cultura e em 1988 promulgada a Constituição Federal, que reforça a responsabilidade do Estado com os direitos culturais, além de, ao descentralizar os recursos, permitir que os governos estaduais e municipais possam investir mais em cultura.

Em 1986, foi implantado pelo MinC o Sistema Nacional de Museus (SNM), que desenvolvia uma política de apoio aos museus baseada em ações descentralizadas e na constatação de que a simples distribuição de recursos era insuficiente para um bom desempenho das instituições museológicas, investindo também no treinamento de recursos humanos. O Sistema Nacional ganhou solo fértil em Santa Catarina, a partir de 1987, com a criação de uma unidade de museus vinculada à nova Secretaria de Cultura e Esportes. Estimulada pela política nacional, essa unidade passou a desenvolver uma série de ações voltadas para as instituições museológicas, criando um sistema estadual que durou até 1990 e foi destaque no contexto nacional.

Essa ação fez com que a Fundação Catarinense de Cultura assumisse um papel central no campo, tornando-se uma importante estrutura de dominação que o influenciou e contribuiu para o aumento do grau de interação entre as organizações, atuando no sentido de democratizar a informação e permitir a adoção de valores mais progressistas no campo, compartilhados com o movimento internacional da nova museologia. ${ }^{6}$

Entre as ações do sistema, houve a destinação de recursos financeiros específicos para os museus, distribuídos por meio da análise de projetos por uma comissão, que produziram a necessidade de estruturação das organizações que desejavam acessar esses recursos, o que envolvia a troca de informações e profissionais. Além disso, o aumento do grau de interação e do volume de informações é percebido também pela realização de oficinas regionais e exposições itinerantes, que foram responsáveis pela capacitação de técnicos e pela articulação entre funcionários de diversas instituições.

Em 1990, Fernando Collor de Mello assumiu a presidência da república. Ocorreu uma crise institucional na cultura, com a extinção da maioria das organizações e programas de cultura federais (Iphan, Funarte e Sistema Nacional de Museus, por exemplo), o rebaixamento do MinC ao status de secretaria e a redução em mais de $50 \%$ do orçamento federal para a área. O segundo momento analisado (de 1991 a 1994) caracterizou-se por um alinhamento do novo governo estadual com a orientação neoliberal que se instalava no contexto nacional. Ocorreu uma ruptura com as práticas adotadas anteriormente, em prol da adoção de uma política voltada para o patrimônio edificado e para a instrumentalização da cultura, da perspectiva do turismo. 
O Sistema Estadual de Museus foi extinto e um novo projeto político para o setor do patrimônio implantado, de valorização do patrimônio material e imaterial por meio do estímulo ao turismo cultural. Esse projeto, que buscava ressaltar as diferenças entre as diversas regiões do estado, adotou valores ligados à lógica do turismo, reforçou a valorização do patrimônio edificado e pouco contribuiu para a interação estadual dos museus.

A nova estrutura da Fundação Catarinense de Cultura passou a contemplar uma diretoria de patrimônio com gerências específicas para os patrimônios material e imaterial e para museus. Ao contrário do que poderia sugerir, essa orientação diminuiu o poder de definir políticas específicas para os museus - dado que a gerência de museus ficou subjugada às prioridades da diretoria de patrimônio -, que passaram a ser a preservação do patrimônio edificado, conciliada com o projeto de desenvolvimento do turismo. Nesse sentido, foi priorizado o mapeamento e tombamento dos bens edificados com valor histórico ou artístico, com o conseqüente comprometimento da estrutura e limitação das verbas do setor para esse projeto.

Constatamos que as ações do governo vinculadas ao campo museal estavam mais restritas aos museus administrados pelo Estado e a uma orientação técnica pouco efetiva aos municípios. Isso evidencia que houve descontinuidade no processo de interação que vinha se estabelecendo no campo, por meio do Sistema Estadual de Museus. Por outro lado, o mapeamento das rotas migratórias e sua vinculação ao turismo podem ter reforçado a regionalização do campo e estabelecido nele valores mais orientados por uma lógica instrumental.

Em paralelo, o Iphan e o MinC, que passavam por uma crise institucional, tiveram pouca presença no campo. Somente em 1994 o Iphan reassumiu seu papel no campo, ao promover a série de oficinas de conservação e restauração já citadas. A partir de 1995, uma coalizão formada por funcionários efetivos da FCC, na área de patrimônio, passou a influenciar o campo museal. Entre 1995 e 2002, o grupo garantiu a nomeação de todos os diretores e gerentes de patrimônio, escolhidos entre os técnicos efetivos da fundação. Se por um lado, essa organização permitiu a continuidade das ações do patrimônio, por outro, prejudicou o desenvolvimento de projetos voltados aos museus, uma vez que as prioridades sempre foram para o patrimônio edificado, em especial, para as questões relacionadas com os tombamentos. Isso, aliado ao grande volume de processos de tombamento herdado da administração anterior, limitou a ação da gerência de museus, que apesar de manter um trabalho de atendimento aos municípios, teve pouca expressão na configuração do campo.

O terceiro momento (de 1995 a 1998) foi marcado por uma ação do governo do estado, na área do patrimônio, muito limitada pela necessidade de manutenção das políticas preservacionistas instauradas no período anterior, que por força da lei mobilizaram os esforços e recursos do setor. Apesar da existência de um projeto de política cultural que envolvia, entre outras ações, a distribuição democrática de recursos financeiros por meio de editais, a pouca estrutura disponível para o setor dos museus, aliada às exigências de recursos técnicos, financeiros e humanos do projeto de tombamento, foram determinantes na manutenção da distância do Estado do campo dos museus.

Na esfera federal, o presidente Fernando Henrique Cardoso realizou a reforma administrativa do Estado brasileiro que produziu o fortalecendo da atuação do mercado e do terceiro setor sem garantir a efetiva participação social. A consolidação de uma nova forma de articular a esfera pública com o mercado teve reflexos nas políticas culturais aplicadas pelo governo catarinense, gerando uma aproximação com a iniciativa privada que produziu um maior desenvolvimento de determinadas áreas artísticas em detrimento de outros setores culturais menos atraentes, como os museus.

O quarto momento (de 1999 a 2002) caracterizou-se por dois aspectos antagônicos das políticas praticadas pelo governo do estado de Santa Catarina: por um lado, pelo projeto patrimonialista presente na promoção do folclore e da tradição popular como núcleo da identidade estadual, que pode ter reforçado a ênfase dos museus municipais com perfil histórico-etnográfico; por outro lado, pela afirmação da lógica mercantil, por meio do desenvolvimento de um projeto turístico associação à imagem de estado multiétnico e a implantação do sistema de incentivo fiscal para apoio a projetos culturais em Santa Catarina.

A pouca autonomia dada à Fundação Catarinense de Cultura (FCC), com a centralização dos principais projetos no gabinete do governador, e a continuação da ação da coalizão de funcionários, que mantinha o foco da diretoria de patrimônio no patrimônio edificado, contribuíram para aumentar o afastamento da FCC do campo. 
A fundação deixa de ser o principal interlocutor do Estado com o campo dos museus, imperando uma política de balcão diretamente ligada ao governador e um sistema de financiamento que privilegiava a adequação ao mercado. Ao mesmo tempo, as demandas do campo que estava se estruturando, que não eram vistas como prioritárias pelo governo, eram cumpridas pelo NEMU.

O quinto momento (2003-2006) foi marcado pela forte influência do contexto institucional nacional. O governo Lula adotou ações federais com grandes reflexos no campo, com a criação do Sistema Brasileiro de Museus e o desenvolvimento da Política Nacional de Museus. Houve também um aumento significativo nas fontes e nos valores para financiamento de projetos museais, assim como a viabilização de oficinas de capacitação e o estímulo à realização de eventos nas semanas dos Museus.

O Sistema Brasileiro de Museus, por meio do Cadastro Nacional de Museus (CNM), ampliou a demanda e o número de informações com que as organizações tiveram que lidar (ao exigir um padrão de entrada de dados, provocou um aumento na organização documental dos museus e produção de reflexões sobre novas informações, como especificidades de segurança e controle patrimonial, por exemplo). A exigência de adequação dos estados e municípios a esse sistema fez a diretoria de patrimônio convocar a classe museológica em 2004 para, juntas, definirem a Política Estadual de Museus e a implantação de um sistema estadual.

Observamos que essas ações estruturais (que devem produzir efeitos no campo quando implementadas) não foram resultantes de uma planejada política estadual. Esta esteve mais focada na ampliação dos recursos para financiamento de projetos e equipamentos culturais, por meio de isenção fiscal, e na descentralização da estrutura administrativa, que retirou poder das mãos dos técnicos, concentrando-o na dos políticos e do mercado.

O governo do estado promoveu a mais ampla reforma administrativa do período analisado, implantando um modelo de descentralização que ampliou o poder do Executivo nos municípios, por meio da criação de dezenas de secretarias regionais e do "enxugamento" da estrutura centralizada. Nesse processo, reuniu a cultura, o esporte, o turismo e o lazer numa mesma secretaria e reduziu a estrutura da Fundação Catarinense de Cultura. Essa reestruturação acabou por diminuir o poder do Executivo para formular políticas culturais, por meio da troca de cargos técnicos na estrutura da FCC por políticos nas secretarias regionais.

$\mathrm{Na}$ área do patrimônio, foi verificada uma abertura às novas orientações vindas do contexto nacional. Possivelmente, porque o governo não possuía um projeto para o setor e via na proposição do governo federal uma forma de superar uma deficiência histórica na relação do Estado com o campo dos museus. Também, porque, ao desmantelar a estrutura da FCC, quebrou com a coalizão dos funcionários da diretoria de patrimônio, que detinham o poder de conduzir as atenções para o patrimônio edificado. No entanto, verificamos que a falta de técnicos capacitados foi um dos grandes desafios enfrentados pela diretoria.

Constatamos nos cinco períodos a descontinuidade de ações públicas na área da cultura, o que se evidencia na ruptura de lógicas, orientações e comportamentos do Estado a cada período. O revezamento de posicionamentos políticos foi uma característica dos governos catarinenses até o ano de 2006, quando, pela primeira vez na história recente das eleições governamentais, houve uma reeleição e, conseqüentemente, a continuidade de um projeto de governo. No entanto, há uma orientação neoliberal subjacente a todos os períodos analisados, que surge com maior ou menor ênfase em determinados momentos. Isso tem como conseqüência o afastamento gradativo do Estado de seu papel regulador, reduzindo os mecanismos de financiamento direto e ampliando o espaço de decisão do mercado, o que dificulta o desenvolvimento de determinadas áreas que têm pouco apelo mercadológico, como a dos museus.

\section{Considerações finais}

A análise nos permitiu verificar que o campo, no período em questão, passou de uma estruturação que o caracterizava como "campo emergente" para outra de "campo em expansão" (VIEIRA; CARVALHO, 2006). Permitiu também destacar, entre todos os atores identificados, a atuação do Estado e do Núcleo de Estudos Museológicos. O Estado apareceu como importante ator, por meio de três estruturas de dominação: a Fundação 
Catarinense de Cultura (FCC), a coalizão de funcionários de sua diretoria de patrimônio e o Instituto do Patrimônio Histórico Artístico Nacional (Iphan).

Verificamos que no primeiro momento (1987-1990), a FCC apareceu como principal ator do campo, assumindo uma posição que se destacava perante as outras organizações de referência. Isso se deu, principalmente, por causa da implantação do Sistema Estadual de Museus. A estruturação do campo, nesse período, parece aproximar-se de um "campo emergente" (VIEIRA; CARVALHO, 2006) e se deu, primeiro, de forma regionalizada, com um aumento no grau de interação das organizações.

No entanto, em virtude da pouca prioridade dada às políticas museológicas pelos governos seguintes, a atuação do Estado, por meio da FCC, reduziu-se a eventos esporádicos. A sua posição entre as mais importantes estruturas do campo só é novamente reivindicada no último período (2003-2006), a partir de uma forte influência do contexto nacional, representado pelo Iphan. Um dos fatores que reforçou o distanciamento da FCC do campo foi a presença de uma coalizão formada por funcionários efetivos da diretoria de patrimônio, que garantiram, de 1995 a 2002, a continuidade de ações mais focadas no patrimônio material (em especial, nas questões relacionadas com os tombamentos), dificultando a implantação de políticas voltadas aos museus.

O vácuo deixado pela FCC contribuiu para o fortalecimento do Núcleo de Estudos Museológicos (NEMU) no campo, reforçado pela legitimação de outras instituições públicas da esfera federal: a UFSC e o Iphan. Desde sua implantação, em 1997, o NEMU foi responsável por importantes mudanças no campo, especialmente, pelo aumento do nível de capacitação e pela integração entre as regiões, fazendo com que a estrutura passasse para a de um "campo em expansão" (VIEIRA; CARVALHO, 2006). Gradualmente, o NEMU foi se institucionalizando no campo como a principal organização realizadora de políticas museológicas de Santa Catarina, contribuindo para a consolidação de um sentimento de pertença ao campo, de comunalidade, além da melhora na qualidade dos serviços realizados pelos museus, da conservação à exposição. No entanto, o formato centralizador do NEMU parece reforçar uma tendência paternalista de dependência das demais organizações à sua atuação, evidenciada pelas fracas ligações horizontais entre os museus.

Apesar de constatarmos que a atuação do NEMU no campo foi inversamente proporcional à da FCC, verificamos que, mesmo na ausência de um projeto para o campo, o Estado (em todas as suas esferas) continuou intervindo na sua configuração. Acreditamos que a ação do NEMU, de certa forma, liberou os sucessivos governos do estado de agirem no campo dos museus, deixando-os livres para se concentrarem nas políticas de preservação ligadas ao patrimônio edificado. Concomitantemente, o governo federal encontrou no NEMU um importante interlocutor no campo. Essa divisão funcional parece ter sido útil ao Estado e ao NEMU.

Com relação ao contexto institucional nacional, representado pelas políticas de patrimônio do Iphan, sua influência direta no campo se faz mais presente a partir de 2003, quando a política de museus contribui para a adoção de novos valores e práticas, especialmente, por meio da implantação do Sistema Brasileiro de Museus.

A partir de 2003, com a reestruturação administrativa no governo catarinense, ocorre um rompimento na coalizão de funcionários que mantinha a continuidade das políticas de preservação ligadas ao patrimônio edificado. A alteração nas relações de poder dentro da diretoria do patrimônio da FCC, conjugada às políticas nacionais do Iphan, abre espaço para iniciativas do Estado voltadas aos museus, como a criação de um novo sistema estadual.

A influência do novo Sistema Estadual de Museus (SEM) no campo ainda é muito recente para que se possa avaliar seu impacto, pois sua regulamentação só ocorreu no final de 2006; embora, com sua implantação, o Estado tenha a chance de retomar seu papel no campo. No entanto, terá de confrontar-se com dois desafios para conseguir que o SEM seja legítimo perante a sociedade: o descrédito dos atores com a atuação da FCC e a posição do NEMU no campo, como a estrutura de dominação estabelecida e que tem mais recursos de poder.

O descrédito dos atores parece relacionado à descontinuidade das ações públicas estaduais e à incapacidade dos governos lidarem com a característica de desconcentração desse campo. Quanto ao NEMU, encontra-se numa posição difícil de ser alterada ou mesmo compartilhada com outros atores, a de principal liderança no campo. 
Contudo, os novos valores que vêem sendo adotados no campo, que fazem com que os atores demandem uma capacitação num nível mais alto, têm provocado questionamentos sobre a posição do NEMU. No entanto, a julgar pelas primeiras ações do Sistema Estadual de Museus, a FCC parece não ter identificado essa mudança no campo, optando por realizar oficinas de capacitação nos moldes das que o NEMU promove, o que produz um conflito de funções.

Acreditamos que a delimitação das funções dos dois programas deva ser prioritária para a eficácia das ações futuras. Atualmente, há uma competição entre NEMU e SEM por recursos e atenções do governo federal, o que os desvia de suas prioridades e dificulta um trabalho colaborativo. O SEM pode ser um importante instrumento na construção participativa de políticas e ações que reflitam as necessidades do campo; enquanto o NEMU pode vir a ser um importante parceiro na articulação e execução das políticas definidas pelo Sistema, que $a$ priori devem ser construídas pelos atores do campo.

No entanto, constatamos a persistência de um caráter paternalista no campo, que precisa ser rompido para que essa cooperação ocorra. Os atores do campo mantêm-se na busca de relações que reproduzam um padrão centralizador e que parece ser reforçado pela atuação do NEMU, assumindo o papel patriarcal que, por vezes, é criticado no Estado. Nesse sentido, parece pertinente afirmar que o NEMU não se constituiu como mais uma instituição do campo produzindo políticas culturais, mas como "a instituição" promotora das políticas do campo, assumindo assim um papel que é também do Estado.

Uma vez que as políticas públicas não são somente aquelas desenvolvidas pelo Estado, mas também pela sociedade civil, a articulação do NEMU traz uma perspectiva democrática ao campo. No entanto, para que essa perspectiva se concretize, faz-se necessária a presença do Estado, que precisa retomar seu papel primordial de mediador e regulador das forças que atuam no campo. Sendo assim, concluímos que o processo histórico de institucionalização do campo museal catarinense deu origem a um conflito entre a atuação do NEMU e da FCC. Este conflito está relacionado ao papel que o NEMU assumiu com a retirada crescente do Estado no campo, que reconfigurou as relações de poder. A atuação de ambos em futuros confrontos é essencial para o desenvolvimento do campo e resultará certamente em novas configurações que merecem ser observadas. 


\section{Referências}

CARVALHO, Cristina A. P. de; PACHECO, Flávia Lopes; GUIMARÃES, Rodrigo Gameiro. Análises organizacionais no campo da cultura e a importância do Estado. In: ENCONTRO DE ADMINISTRAÇÃO PÚBLICA E GOVERNANÇA, 1., 2004, Rio de Janeiro. Anais... Rio de Janeiro: Anpad, 2004. 1 CD-ROM.

; VIEIRA, Marcelo Milano Falcão (Org.). Organizações, cultura e desenvolvimento local: a agenda de pesquisa do Observatório da Realidade Organizacional. Recife: Edufepe, 2003.

CHAGAS, Mário. Museus: antropofagia da memória e do patrimônio. In: (Org.). Revista do Patrimônio Histórico e Artístico Nacional, n.31, Iphan, 2005.

CROZIER, Michel. A sociedade bloqueada. Brasilia: Editora UnB, 1983.

DIMAGGI0, Paul, J. Construcción de um campo organizacional como un proyecto profesional: los museos de arte de los Estados Unidos, 1920-1940. In: POWELL, Walter W.; DIMAGGIO, Paul J. (Org.). El nuevo institucionalismo en el análisis organizacional. México: FCE, 1999. p.333-361.

; POWELL, Walter W. Introducción. In: POWELL, Walter W.; DIMAGGIO, Paul J. (Org.). El nuevo institucionalismo en el análisis organizacional. México: FCE, 1999. p.33-75.

A gaiola de ferro revisitada: isomorfismo institucional e racionalidade coletiva nos campos organizacionais. Revista de Administração de Empresas - RAE, São Paulo, n.2, v.45, p.74-89, abr./jun. 2005.

FARIA, José Henrique de. Economia política do poder. Curitiba: Juruá, 2004. v.3. 202 p

FCC - Fundação Catarinense de Cultura (Santa Catarina). Guia de museus de Santa Catarina. Florianópolis, 2001

GOULART, Sueli; MENEZES, Michelle Ferreira de; GONÇALVES, Júlio César. Composição e características do campo organizacional dos museus e teatros da região metropolitana do Recife. In: CARVALHO, Cristina Amélia; VIEIRA, Marcelo Milano Falcão (Org.). Organizações, cultura e desenvolvimento local: a agenda de pesquisa do Observatório da Realidade Organizacional. Recife: Edufepe, 2003. p.123-135.

HALL, Peter; TAYLOR, Rosemary C. R. As três versões do neo-institucionalismo. Lua Nova, Cedec, São Paulo, n.58, p.193-223, 2003.

IPHAN - Instituto do Patrimônio Histórico e Artístico Nacional. Cadastro Nacional de Museus. Disponível em: <www.cultura.gov.br>. Acesso em: 7 out. 2006.

JEPPERSON, Ronald L. Instituciones, efectos institucionales e institucionalismo. In: POWELL, Walter W.; DIMAGGIO, Paul J. (Org.). El nuevo institucionalismo en el análisis organizacional. México: Universidad Autónoma del Estado de México, 1999. p.193-215.

KORPI, Walter. Power resources approach vs. action and conflict: on causal and intentional explanations in the study of power. Sociological Theory, v.3, n.2, p.31-45, autumn 1985.

MACHADO-DA-SILVA, Clóvis L. et al. Institucionalização da mudança na sociedade brasileira: o papel do formalismo. In: VIEIRA, Marcelo M. F.; CARVALHO, Cristina A. (Org.). Organizações, instituições e poder no Brasil. Rio de Janeiro: Editora FGV, 2003. p.179-202.

MEYER, John W.; ROWAN, Brian. Organizaciones institucionalizadas: la escructura formal como mito y ceremonia. In: POWELL, Walter W.; DIMAGGIO, Paul J. (Org.). El nuevo institucionalismo en el análisis organizacional. México: Universidad Autónoma del Estado de México, 1999. p.79-103.

MORGAN, Gareth. Imagens da organização. São Paulo: Atlas, 1996.

OLIVEN, Ruben George. A parte e o todo: a diversidade cultural no Brasil-nação. Petrópolis: Vozes, 1992.

PAULILLO, Luiz Fernando. Rede de relações e poder de negociação: uma análise do caso citrícola brasileiro. Gestão e Produção, São Carlos, v.8, n.3, p.250-270, dez. 2001.

RANSON, S.; HINNINGS, B.; GREENWOOD, R. The structuring of organizational structures. Administrative Science Quarterly, v.25, n.1, p.1-17, 1980. 
SANTOS, Myrian Sepúlveda dos. Museus brasileiros e política cultural. Revista Brasileira de Ciências Sociais, Associação Nacional de PósGraduação e Pesquisa em Ciências Sociais, São Paulo, v.19, n.55, p.53-72, jun. 2004.

SAYÃO, Thiago J. Nas veredas do folclore: leituras sobre política cultural e identidade em Santa Catarina (1948-1975). Dissertação (Mestrado em História) - Pós-Graduação em História, UFSC, Florianópolis, 2004.

SCOT, W. Richard. Toward a theoretical synthesis. In: SCOT, W. Richard; MEYER, John W. Institutional environments and organizations: structural complexity and individualism. London: Sage, 1994.

Institutions and organizations. London: Sage, 2001.

; MEYER, John W. La organización de los sectores socials: proposiciones y primeras evidencias. In: POWELL, Walter W.; DIMAGGIO, Paul J. (Org.). El nuevo institucionalismo en el análisis organizacional. México: Universidad Autónoma del Estado de México, 1999. p.154-187.

VIEIRA, Marcelo M. F.; CARVALHO, C. A. Campos organizacionais da cultura: de wallpaper à construção histórica do contexto de organizações culturais no Brasil. In: TAVARES, R. R. (Org.). Língua, cultura e ensino. Maceió: Edufal, 2006.

; SILVA, Rosimeri C. Influence du contexte institutionel dans le champ des musées et théatres de deux régions du

Brésil. 2007. Working paper.

; PEREIRA, Bill Nunes. Estudos etnográficos em administração. In: VIEIRA, Marcelo Milano F.; ZOUAIN, Deborah Moraes. Pesquisa qualitativa em administração: teoria e prática. Rio de Janeiro: FGV Editora, 2005. p.223-237.

\section{Notas}

Santa Catarina é o terceiro estado do país com melhor distribuição dos museus pelas cidades (IPHAN, 2006).

2 Segundo relatório da divisão de ciências do Departamento de Cultura da Secretaria de Educação e Cultura de Santa Catarina, de 1974 - Arquivo da Diretoria de Patrimônio da FCC.

3 Segundo documentos dos arquivos da Diretoria de Patrimônio da FCC e pesquisa realizada por Santos (2004), a partir de dados de 1997 obtidos pela Comissão do Patrimônio Cultural da Universidade do Estado de São Paulo (CPC/USP).

4 Segundo dados do Guia de Museus de Santa Catarina (FCC, 2001).

5 O estudo consistiu em reexaminar investigações que estudaram, entre outros aspectos, a composição, as características, a formação e a estruturação do campo organizacional dos museus e teatros das regiões metropolitanas de Recife e Porto Alegre; a ampliação do contexto de referência institucional da representação da Paixão de Cristo em Nova Jerusalém; bem como a configuração organizacional dos grupos de maracatu de Recife (CARVALHO, PACHECO; GUIMARÃES, 2004).

6 Movimento iniciado em 1972, que buscou romper com os preceitos tradicionais de que o prioritário no museu é a coleção. Afirmou a função social deste, trazendo para o primeiro plano a comunidade e incorporando aos museus o aspecto transformador por meio da educação. 